\title{
Periodic Existence of Mycorrhizal Fungi in Roots and Non-root Dissident Portions of Some Bulbous Plants
}

\section{Muhammad Ali*, Muhammad Adnan and Mehra Azam}

Institute of Agricultural Sciences, University of the Punjab, Lahore-54590, Pakistan

\begin{abstract}
Decaying and senescing scale-like leaves and roots were collected regularly from Botanical Garden, University of the Punjab, Lahore for a period of four months, with an interval of fifteen days. Roots and other portions of both the plants when processed and examined revealed the occurrence of AM fungal structures. However, AM structures were totally missing in Allium cepa, and roots of Amaryllis vittata. Thick hyphal mats with clusters and clumps of spores were often seen in the decaying scale-leaves. The vesicles in these portions were large sized and thick walled. As regard the seasonal variations, the side by side of hyphal, arbuscular and vesicular infections varied among the samples collected throughout the season. Seasonal variations in Glomalean spore dynamics were observed with respect to number while glomeromycetous species richness varied in the rhizosphere soil of the three plants. The recent research was conducted to evaluate the configuration of occurrence of arbuscular mycorrhizal fungal structures in decaying scale like leaves and root system of three bulbous plants i.e., Allium cepa, Amaryllis vittata and Zaphyranthes citrina.
\end{abstract}

Keywords: Arbuscular mycorrhizae; Scale-leaves; Allium cepa; Amaryllis vittata; Zaphyranthes citrine; Species richness

\section{Introduction}

Arbuscular Mycorrhizae (AM) is mutually beneficial relationship amongst fungi and roots of the higher plants. Colonization of roots by mycorrhiza has been revealed to recover development and yield of numerous field crops including leguminous crops, cereals, vegetables and oil crops [1-5]. Mycorrhizal associations increase plant growth and productivity by increasing nutrient element uptake [6] and improving resistance to abiotic $[7,8]$ and biotic [9] stress factors. Plants often benefit from the presence of mycorrhizal associates via a variety of mechanisms including improvement of soil structure, mobilization of essential minerals, enhancement of desiccation resistance, and protection from pathogens and herbivores [10]. Recently some workers have reported that AM also increase the crop tolerance against allelopathy and enhance crop growth under this stress [11,12].

Vesicular arbuscular mycorrhizae are of universal occurrence in roots of $95 \%$ of land plants $[13,14]$. However, during past few decades reports are available about the presence of AM in plant portions other than roots $[15,16]$. Since than a number of examples have been added to the literature with an emphasis on a much wider occurrence of these associations than reported ever before.

We had planned this study to further add to the information about $\mathrm{AM}$ proliferating in roots and non-root portions of some bulbous plants.

\section{Materials and Methods}

Sampling of root and non-root portions like scale leaves, dried decaying sheathing leaves on the bulbs of two test bulbous plants viz. Allium cepa, Amaryllis vittata and Zaphyranthes citrina. The sampling was done regularly from February to May. Specific sites (Sites name) were selected for sampling of plants. The root/bulb samples were dug up along with rhizospheric soil. Extreme care was taken to avoid the disturbance of root systems, adhering decayed and semi-decayed scale leaves and epidermis. The samples were brought back to the Lab. in polythene bags. Decaying scale like leaves and fine roots were gently peeled off with the help of forceps, while rest of the bulbous portion along with root system were dipped in a bucket of water for half an hour. The adhering soil was removed with the help of camel hairbrush while washing gently under the tap water. The root system of all samples, scales and other portions were cut up into $1 \mathrm{~cm}^{2}$ pieces and then fixed in F.A.A. (Formaline: Acetic Acid : Alcohol in 5:5:90 ratio by volume) in properly labeled MacCartney bottles separately. The samples were cleared and stained for analysis of colonization of AM fungi using Phillips and Hayman procedure [15]. The roots were cleared in $10 \%$ $\mathrm{KOH}$ solution in an autoclave, placed in $0.1 \mathrm{~N} \mathrm{HCl}$ for 2-3 minutes for neutralization and then stained with trypan blue solution $(0.05 \%$ in lactophenole glycerine). The sample pieces were mounted on the glass slides in a drop of lactic acid and were observed under low power (10x) of the light microscope. Extent of AM infection was recorded with the help of an already calibrated ocular micrometer. This was done by randomly focusing the plant material under the microscope and by measuring the hyphae. The number of vesicles and other structures were also recorded in the same way. Microphotography was done with the help of Minolta X 700 camera with the adapter tube.

Soil adhering to the roots and other portions like bulbs were utilized for screening the associated AM spores. Spore extraction was done by following wet sieving decanting method of Nicolson and Gerdemann $[11,12]$. Density and diversity of spores was recorded. Spores were identified using synoptic key by Morton [16] and Schenck and Perez [17]. All the data was statistically analyzed by computing Standard

*Corresponding author: Muhammad Ali, Institute of Agricultural Sciences, University of the Punjab, Lahore-54590, Pakistan, Tel: +92-331-4478569; E-mail: muhammadali.mycologist@gmail.com

Received January 19, 2015; Accepted January 25, 2015; Published January 30, 2015

Citation: Ali M, Adnan M, Azam M (2015) Periodic Existence of Mycorrhizal Fungi in Roots and Non-root Dissident Portions of Some Bulbous Plants. J Plant Pathol Microb 6: 248. doi:10.4172/2157-7471.1000248

Copyright: @ 2015 Ali M, et al. This is an open-access article distributed under the terms of the Creative Commons Attribution License, which permits unrestricted use, distribution, and reproduction in any medium, provided the original author and source are credited. 
Citation: Ali M, Adnan M, Azam M (2015) Periodic Existence of Mycorrhizal Fungi in Roots and Non-root Dissident Portions of Some Bulbous Plants. J Plant Pathol Microb 6: 248. doi:10.4172/2157-7471.1000248

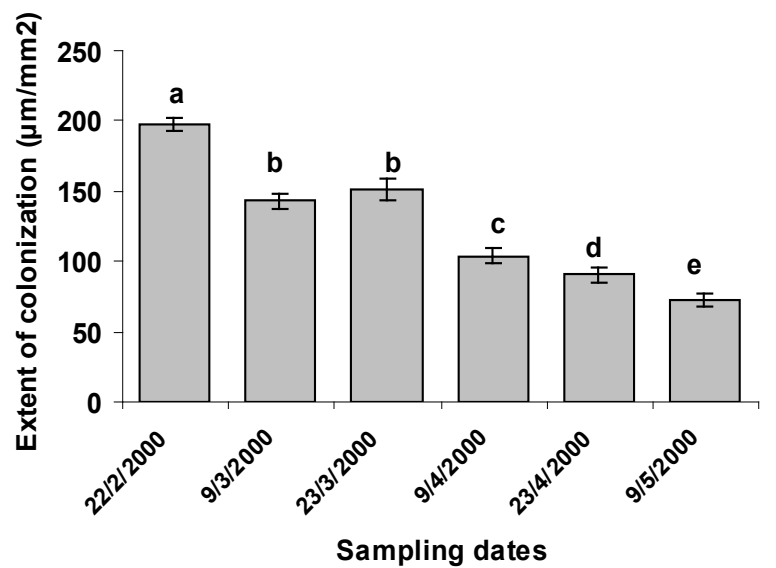

Figure 1: Seasonal changes in extent of AM colonization in root system of Amayrllis vittata. Line on data bars show SE of the mean while data bars with different letters show significant difference $(p=0.05)$ as determined by DMRT.

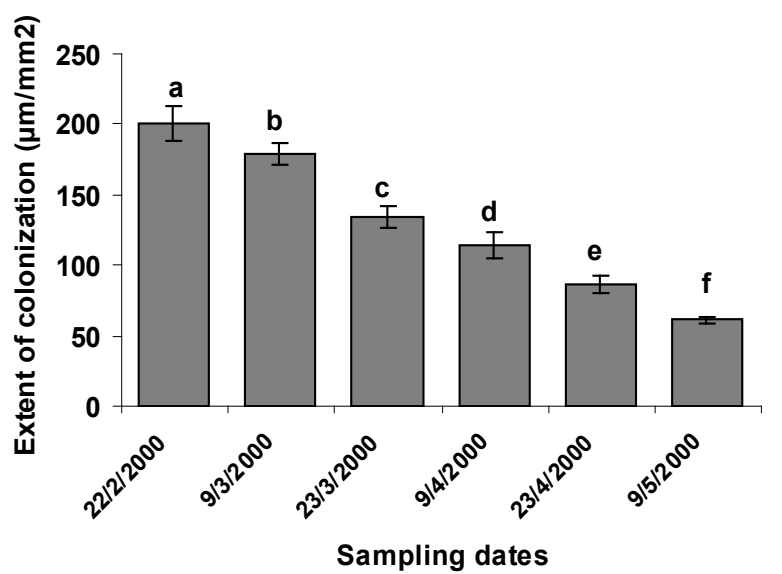

Figure 2: Seasonal changes in status of $A M$ infection in root system of Zaphyranthes citrina. Line on data bars show SE of the mean while data bars with different letters show significant difference $(p=0.05)$ as determined by DMRT.

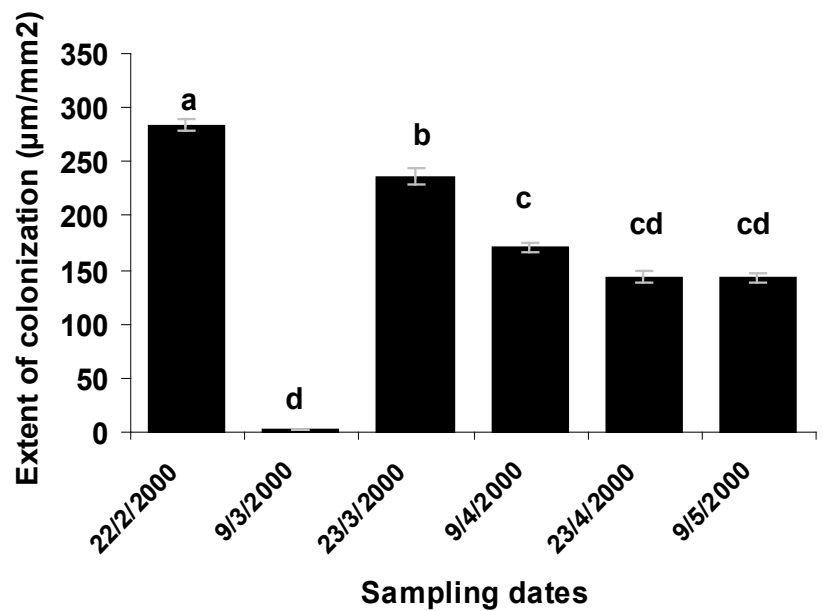

Figure 3: Seasonal changes in status of AM infection in decaying scale leaves of Zaphyranthes citrina. Line on data bars show SE of the mean while data bars with different letters show significant difference $(p=0.05)$ as determined by DMRT.

Error, Least Significant Difference; (LSD) and Duncan's New Multiple Range Test (Steel and Torrie [18].

\section{Result and Discussion}

AM colonization was completely absent in scales and roots of Allium cepa, and roots of Amaryllis vittata (members of Amaryllidaceae) may be attributed to existence of immunity to attack by pathogenic fungi. In bulbs of Allium cepa resistance to attack by fungus is due to the presence of catecol and protocatechuic acid in the dry, pigmented, outer scale leaves. Members of Amaryllidaceae also produce fungitoxin (Methylene-buty rolactose) in their bulbs, which also diffuses to plant roots (Figures 1-3) and (Tables 1-3).

\begin{tabular}{|c|c|c|c|c|}
\hline Sample No & Sampling date & No. of vesicles per $\mathbf{~ m m}^{2}$ & $\begin{array}{c}\text { No. of Intramatrical spores } \\
\text { per } \mathbf{~ m m}^{\mathbf{2}}\end{array}$ & No. of cells filled with DSEF per $\mathbf{m m}^{\mathbf{2}}$ \\
\hline 1. & $22 / 2 / 2000$ & $000.77 \mathrm{~d} \pm 0.29$ & $002.44 \mathrm{e} \pm 0.94$ \\
\hline 2. & $9 / 3 / 2000$ & $002.66 \mathrm{~b} \pm 0.577$ & $003.66 \mathrm{~d} \pm 1.33$ & $008.66 \mathrm{e} \pm 0.66$ \\
\hline 3. & $23 / 3 / 2000$ & $002.66 \mathrm{~b} \pm 1.00$ & $005.33 \mathrm{c} \pm 0.19$ & $007.33 \mathrm{f} \pm 2.33$ \\
\hline 4. & $9 / 4 / 2000$ & $002.44 \mathrm{c} \pm 0.1$ & $007.99 \mathrm{~b} \pm 0.51$ & $013.66 \mathrm{~d} \pm 1.76$ \\
\hline 5. & $23 / 4 / 2000$ & $002.88 \mathrm{a} \pm 0.39$ & $012.66 \mathrm{a} \pm 3.38$ & $016.00 \mathrm{~b} \pm 0.57$ \\
\hline 6. & $9 / 5 / 2000$ & $002.44 \mathrm{c} \pm 1.25$ & $012.10 \mathrm{a} \pm 2.27$ & $018.00 \mathrm{a} \pm 4.04$ \\
\hline
\end{tabular}

Table 1: Status of various AM structures in decaying scale like leaves of Amaryllis vittata at different sampling time.

\begin{tabular}{|c|c|c|c|c|}
\hline Sample No & Sampling month & No. of vesicles per $\mathrm{mm}^{2}$ & No. of Intramatrical spores per $\mathrm{mm}^{2}$ & No. of cells filled with DSEF per $\mathrm{mm}^{2}$ \\
\hline 1. & $22 / 2 / 2000$ & $011.00 \mathrm{a} \pm 0.57$ & $003.66 \mathrm{c} \pm 1.76$ & -- \\
\hline 2. & $9 / 3 / 2000$ & $010.00 b \pm 1.52$ & $003.66 c \pm 0.33$ & -- \\
\hline 3. & $23 / 3 / 2000$ & $010.33 b \pm 1.45$ & $003.66 c \pm 0.33$ & $001.33 c \pm 0.33$ \\
\hline 4. & $9 / 4 / 2000$ & $008.88 c \pm 3.39$ & $003.89 d \pm 0.39$ & $006.00 b \pm 3.00$ \\
\hline 5. & $23 / 4 / 2000$ & $006.33 d \pm 0.03$ & $005.33 b \pm 0.33$ & -- \\
\hline 6. & $9 / 5 / 2000$ & $005.33 e \pm 0.57$ & $006.33 a \pm 0.36$ & $007.33 a \pm 0.88$ \\
\hline \multicolumn{2}{|c|}{ L.S.D } & 1.77 & 1.48 & 2.42 \\
\hline
\end{tabular}

Table 2: Status of various AM structures in root systems of Zaphyranthes citrina at different sampling times. 
Citation: Ali M, Adnan M, Azam M (2015) Periodic Existence of Mycorrhizal Fungi in Roots and Non-root Dissident Portions of Some Bulbous Plants. J Plant Pathol Microb 6: 248. doi:10.4172/2157-7471.1000248

Page 3 of 3

\begin{tabular}{|c|c|c|c|c|}
\hline Sample No & Sampling date & No. of vesicles per $\mathrm{mm}^{2}$ & No. of Intramatrical spores per $\mathrm{mm}^{2}$ & No. of cells filled with DSEF per $\mathrm{mm}^{2}$ \\
\hline 1. & $22 / 2 / 2000$ & $032.55 a \pm 1.25$ & $004.00 \mathrm{e} \pm 0.57$ & $008.66 \mathrm{a} \pm 2.40$ \\
\hline 2. & $9 / 3 / 2000$ & $030.77 b \pm 0.83$ & $005.33 d \pm 0.66$ & $004.66 c \pm 0.33$ \\
\hline 3. & $23 / 3 / 2000$ & $026.21 c \pm 0.29$ & $011.33 e \pm 1.45$ & $005.33 b \pm 1.53$ \\
\hline 4. & $9 / 4 / 2000$ & $023.88 d \pm 1.68$ & $022.00 d \pm 1.52$ & $004.00 c \pm 1.73$ \\
\hline 5. & $23 / 4 / 2000$ & $018.32 \mathrm{e} \pm 1.33$ & $030.33 a b \pm 1.85$ & $003.66 d \pm 0.88$ \\
\hline 6. & $9 / 5 / 2000$ & $015.55 f \pm 1.56$ & $032.00 a \pm 0.57$ & $003.33 d \pm 1.20$ \\
\hline \multicolumn{2}{|c|}{ L.S.D } & 2.35 & 2.30 & 2.76 \\
\hline
\end{tabular}

Table 3: Status of various AM structures in scale leaves of Zaphyranthes citrina at different sampling times.

\section{References}

1. Javaid A, Iqbal SH, Hafeez FY (1994) Effect of different strains of Bradyrhizobium and two types of vesicular arbuscular mycorrhizae (VAM) on biomass and nitrogen fixation in Vigna radiate (L.) Wilzek var. NM 20-21.Sci Inter (Lahore) 6: 265-267

2. Yao MK, Tweddell RJ, Désilets H (2002) Effect of two vesicular-arbuscular mycorrhizal fungi on the growth of micropropagated potato plantlets and on the extent of disease caused by Rhizoctonia solani. Mycorrhiza 12: 235-242.

3. Kapoor R, Giri B, Mukerji KG (2004) Improved growth and essential oil yield and quality in Foeniculum vulgare mill on mycorrhizal inoculation supplemented with P-fertilizer. Bioresour Technol 93: 307-311.

4. Subramanian KS, Santhanakrishnan $P$, Balasubramanian $P(2006)$ Responses of field grown tomato plants to arbuscular mycorrhizal fungal colonization under varying intensities of drought stress. Sci Hortic 107: 245-253.

5. Wang FY, Lin XG, Yin R, Wu LH (2006) Effect of arbuscular mycorrhizal inoculation on the growth of Elsholtzia splendens and Zea mays and the activities of phosphatase and urease in a multi-metal-contaminated soil under unsterilized conditions. Appl Soil Ecol 31: 110-119.

6. Al-Karaki GN (2002) Benefit, cost and phosphorus use efficiency of mycorrhizal field grown garlic at different soil phosphorus levels. J Plant Nutrition 25: 11751184.

7. Feng G, Zhang FS, Li XL, Tian CY, Tang C, et al. (2002) Improved tolerance of maize plants to salt stress by arbuscular mycorrhiza is related to highe accumulation of soluble sugars in roots. Mycorrhiza 12: 185-190.

8. Chen BD, Zhu YG, Smith FA (2006) Effects of arbuscular mycorrhizal inoculation on uranium and arsenic accumulation by Chinese brake fern (Pteris vittata L.) from a uranium mining-impacted soil. Chemosphere 62: 1464-1473.
9. St. Arnaud M, Hamel C, Caron M, Fortin JA (1994) Endomycorrhize VA et sensibilite des plantes aux maladie. In: Fortin JA, Charest $C$ and Piche $Y$ (eds.) La Symbiose Mycorhizienne, Etat des Connaisances, Orbis, Quebec.

10. Bajwa R, Javaid A, Haneef A (1999) EM and VAM technology in Pakistan $\mathrm{N}$ : Response of Cowpea to co-inoculation with EM and VAM under allelopathicstress. Pak. J. Botany. 31: 387-369.

11. Nicolson TH (1967) Vesicular arbuscular mycorrhiza, a universal plant symbionts.

12. Gerdemann JW (1968) Vesicular arbuscular mycorrhizae and plant growth Annual Review of Phytopathology 6: 39-418.

13. Bagyaraj DJ, Manjunath A, Patal RB (1979) Occurrence of vesicular arbuscula mycorrhiza in some tropical aquatic plants. Trans Brit Mycol Soc 72: 164-167.

14. Nasim G (1990) Vesicular arbuscular mycorrhiza in portions other than roots In: Bushan L. Jalali, Chand L (eds.) Current trends in mycorrhizal research. Proceedings of the national conference on mycorrhiza. A Haryana Agr Uni Hisar 14-16: 4-6.

15. Philips JM, Gerdeman DS (1970) Improved procedure for clearing and staining parasitic and VAM fungi for the rapid assessment of infection. Irans. Brit. Mycol. Soc., 55: 158-161.

16. Morton JB (1988) Taxonomy of mycorrhizal fungi. Classification, nomenclature and identification, Mycotoxicon 100: 267-3240.

17. Schenck NC, Perez Y (1987) Manual for the identification of VAM fungi. In VAM, 1453.

18. Steel RDG, Torrie JH (1980) principles and procedure of statistics. McGraw Hil Book Co., Inc. New York USA. 